\title{
CHEMICAL INTERACTIONS IN MULTIMETAL/ZEOLITE CATALYSTS
}

\author{
Progress Report
}

for Period January 7, 199 - January 6, 1999

Wolfgang M. H. Sachtler

Evanston, Illinois 60208-3000

November 1991

\section{DISCLAIMER}

This report was prepared as an account of work sponsored by an agency of the United States Government. Neither the United States Government nor any agency thereof, nor any of their employees, makes any warranty, express or implied, or assumes any legal liability or responsibility for the accuracy, completeness, or usefulness of any information, apparatus, product, or process disclosed, or represents that its use would not infringe privately owned rights. Reference herein to any specific commercial product, process, or service by trade name, trademark, manufacturer, or otherwise does not necessarily constitute or imply its endorsement, recommendation, or favoring by the United States Government or any agency thereof. The views and opinions of authors expressed herein do not necessarily state or reflect those of the United States Government or any agency thereof.

\section{Prepared for}

THE U. S. DEPARTMENT OF ENERGY AGREEMENT NO. DE-FG02-87ER13654 
- Progress Report on DOE project DE FG02-87ERA $13654-8$

Project Title:

\title{
Chemical Interactions in Multimetal/Zeolite Catalysts
}

\author{
Principal Investigator: W. M. H. SACHTLER
}

Project year: 1991/01/07 - 1992/01/06

Research in 1991 under this contract is perceived by our group as being quite fruitful. The mechanisms operating in the formation of bimetal (alloy) particles inside $Y$ zeolites have been studied in detail. The simple view that the more noble metal is reduced first, such that its clusters will serve as nuclei for the reduction of the less noble metal, has been verified for the case of $\mathrm{Pd}+\mathrm{Ni}$, but simultaneously it has been shown that two other mechanisms are also contributing. In this research it was of great help that our earlier discovery could be confirmed that zeolite protons selectively oxidize the atoms of the less noble metal in each alloy particle. This "leaching" leads to a situation where all atoms of one metal are present as clusters, while all atoms of the other metal in the same zeolite are present as cations; when a sample in this situation is reduced again, the reduction mechanism is unambiguous and the concomitant TPR peaks can be assigned. Leaching has now been confirmed for $\mathrm{Pt}+\mathrm{Cu}, \mathrm{Pd}+\mathrm{Cu}$ and $\mathrm{Pd}+\mathrm{Ni}$ in $\mathrm{Y}$ zeolite.

One conclusion from this "leaching" evidence is that the alloy particles must be inside the zeolite when they are leached, so that protons can attack them and local electroneutrality remains maintained. As this was also found to be the case for particles which are larger than the zeolite cages it contradicts the widely held view that zeolites are absolutely rigid and metal particles can only grow outside the zeolite matrix at the external surface. Our results suggest that growing metal or alloy particles locally destroy the zeolite matrix, creating so-called "voids". This is supported by the consistency of XRD and XPS data: XRD of the metal shows particle growth by decreasing width of the diffraction lines of the metal; XRD of the zeolite shows concomitant loss of zeolite crystallinity; XPS shows that the metal/silicon intensity ratio widely deviates from the 
predictions of the model which assumes growth at the external surface only. We shall try to find more evidence verifying the local destruction of the zeolite matrix due to metal particle growth.

In another approach we studied the potential for redispersion of large metal or alloy particles in zeolites, i.e. in situ rejuvenation of catalysts after substantial sintering of the metal. This approach turned out to be very successful. Our strategy is to first oxidize the metal and let the resulting ions disperse in small cages throughout the zeolite matrix. Subsequent reduction under mild conditions results in small metal particles. We found, however, that the oxidative redispersion is limited by the availability of protons in the immediate proximity of the metal particle to be dispersed. We ultimately succeeded in inventing a novel procedure to enable more remote protons to participate in this process; this resulted in virtually complete dispersion of initially very large metal particles. The potential to obtain patent rights for this finding is now under study by a lawyer under contract with Northwestern University.

In a parallel approach we used gaseous chlorine for the redispersion of palladium: this procedure is so effective that even a mechanical mixture of commercially available palladium powder with zeolite $\mathrm{HY}$ could be converted into highly dispersed $\mathrm{Pd} / \mathrm{HY}$.

The bimetallic catalysts $\mathrm{PdNi} / \mathrm{NaY}, \mathrm{PdNi} / \mathrm{HY}$ and $\mathrm{PdCo} / \mathrm{NaY}$ have been tested for the hydrogenation of carbon monoxide; $\mathrm{PtCu} / \mathrm{NaY}$ and $\mathrm{PdCo} / \mathrm{NaY}$ also for the conversion of neopentane. The catalytic performance deviated in all cases distinctly from that calculated for a linear combination of the corresponding monometal catalysts. This deviation from additivity holds for catalyst activity, selectivity and stability against poisoning.

The selectivity of zeolite supported $\mathrm{PdNi}_{\mathrm{x}}$ alloys for methane formation from $\mathrm{CO}$ $+\mathrm{H}_{2}$ is significantly higher than that of monometallic $\mathrm{Pd}$ or Ni catalysts or their physical mixtures. On mixed $\mathrm{PdNi}_{x}$ ensembles the rate of $\mathrm{CO}$ dissociation and/or $\mathrm{CH}_{\mathrm{x}}$ hydrogenation appears to be enhanced with respect to monometallic ensembles. Acid "leaching" of $\mathrm{Ni}$ by zeolite protons from alloy particles leads to restoration of $\mathrm{Pd}$ ensembles and thus an enhanced selectivity to methanol and its consecutive produrts, dimethyl ether and higher hydrocarbons. 
- Neopentane conversion is catalyzed by zeolite encaged PdCo particles. Activity and selectivity strongly depend on the pretreatment conditions. The selectivity of $\mathrm{PdCo} / \mathrm{NaY}$ catalysts is higher for isomerization and lower for hydrogenolysis than that of $\mathrm{Pd} / \mathrm{NaY}$, in conformity with previous results on $\mathrm{SiO}_{2}$ supported $\mathrm{Pd}$ and $\mathrm{PdCo}$. This is remarkable, since reduced $\mathrm{Co} / \mathrm{SiO}_{2}$ displays $100 \%$ selectivity for hydrogenolysis. The isomerization selectivity thus appears a useful yardstick for the extent of alloying between $\mathrm{Pd}$ and $\mathrm{Co}$. The activity appears to be maximum for alloys containing minute amounts of $\mathrm{Co}$. At present $\mathrm{CO}$ hydrogenation by $\mathrm{PdCo} / \mathrm{NaY}$ and $\mathrm{PdCo} / \mathrm{HY}$ is under study and this will be continued in the next year.

Papers published and explicitly acknowledging support by this DOE contract are listed in the attached Tables. As the annual report has to be written before the end of the calendar year, we enclose also the list for 1990. One paper in 1991 is basically a review of previous results; in this paper $(\# 6,1991)$ work sponsored by DOE and NSF is mentioned; in that particular case support by both agencies is acknowledged. At present the PI is engaged, together with Dr. Z. Zhang, in writing a more comprehensive review paper for Advances in Catalysis.

In 1991 two awards to the II have been announced: the lectureship award (DGKM-Kolleg) of the German Scientific Society for Petroleum, Natural Gas and Coal, and the 1992 American Chemical Society award in Petroleum Chemistry. 
Papers by W. M. H. SACHTLER, acknowledging DOE Support, Published in 1990

1. "Transition Metal Clusters and Isolated Atoms in Zeolite Cages"; W.M.H.Sachtler, in "Chemistry and Physics of Solid Surfaces" (Proceedings of ISISS, Milwaukee, Aug.21-24, 1989; R. Vanselow and R. Howe Eds. Springer Series in Surface Sciences 22, Springer Verlag Berlin etc.) 1990, p. 69-85.

2. "Chemisorption and Catalysis of Zeolite Entrapped Palladium"

S. T. Homeyer, Z. Karpiński, W.M.H. Sachtler, Recl. Trav. Chim. Pays-Bas (J. Roy. Neth. Chem Soc.) 109 81-86 (1990)

3. "Location, Ligancy and Reducibility of Metal Ions in Zeolite Cages: Co and $\mathrm{Pd}$ in NaY" Z.-C Zhang and W.M.H. Sachtler, J. Chem. Soc. Faraday Trans. $1990 \underline{86}$ (12) 2313-2319

4. "Effect of Zeolite Protons on Palladium-Catalyzed Hydrocarbon Reactions" S.T. Homeyer, Z. Karpinski, W.M.H. Sachtler; J. Catalysis $1990 \underline{123}$ 60-73

5. "Palladium Enhanced Reducibility of $\mathrm{Ni}$ in $\mathrm{NaY}$ Jennifer Schaefer Feeley and Wolfgang M.H.Sachtler; Zeolites 1990 10 738-745

6. Chemical Interaction of Pd Particles with Fe ions in NaY S. T. Homeyer, L. L. Sheu, Z. Zhang, W.M.H. Sachtler, V. R. Balse, and J. A. Dumesic; J. Applied Catalysis $1990 \underline{64}$ 225-241

7. "Identification by Diffuse Reflectance and EXAFS of the Changes in Coordination of $\mathrm{NaY}$ entrapped $\mathrm{Pd}\left(\mathrm{NH}_{3}\right)_{x}{ }^{2+}$ Ions During Calcination" Zongchao Zhang, Wolfgang M. H. Sachtler, and Huaiyu Chen; Zeolites 1990 10, 784-789

8. Oxidative Redispersion of Metals in Zeolites: The Effect of Ammonia on Pd/HNa Y Rejuvenation; Owen Feeley, Wolfgang Sachtler J. Applied Catalysis 67 (1990) $141-150$ 
Papers by W. M. H. SACHTLER, acknowledging DOE Support, Published in 1991

1. "Effects of Acidity and Metal Ensemble Sizes on the Coke Formation in $\mathrm{Pt} / \mathrm{NaY}$ and $\mathrm{PtCu} / \mathrm{NaY}$ by Methylcyclopentane Conversion" Z. Zhang, G. Moretti, G. Alameddin, and W.M.H. Sachtler; in: Catalyst Deactivation 1991, C.H. Bartholomew and J.B. Butt, Eds. (1991 Elsevier Science Publ. B.V., Amsterdam) Vol 68 of "Studies in Surface Science and Catalysis" pp 727-733

2. "Oxidative Leaching of $\mathrm{Cu}$ atoms from PdCu Particles in Zeolite $Y$ " Zongchao Zhang, Liqiang $\mathrm{Xu}$, and Wolfgang M.H. Sachtler; J. Catal. 131 502-512 1991

3. "Mechanisms of the Formation of $\mathrm{PdNi}_{\mathrm{x}}$ Particles in Cages of NaY"; Jennifer S. Feeley, Z. Zhang, and W.M.H. Sachtler, J. Catal. 131 573-581 1991

4. "Temperature Programmed Surface Reaction of Methylcyclopentane on Pd/NaY and Pd/HY"; Xinlai Bai and Wolfgang M. H. Sachtler

J. Catal. 1321991 266-268

5. "IR-Spectroscopic Study of $\mathrm{Pt} / \mathrm{KL}$ Zeolites using Adsorption of $\mathrm{CO}$ as a molecular probe" Leonid M. Kustov, Daniel Ostgard, Wolfgarng M.H.Sachtler; Catal. Letters g 1991 121- 126

6. "Coordination, Atom Reorganization, and Catalysis of Palladium in Zeolite Cages" Wolfgang M.H. Sachtler, Fernando Cavalcanti and Zongchao Zhang; Catal Lett. 9 $1991261-272$

7. "Enhanced Reducibility of $\mathrm{Ni}$ and $\mathrm{Ni}+\mathrm{Pd}$ in zeolite $\mathrm{Y}$ : Blocking of Small Cages with $\mathrm{Ca}^{2+}$ or $\mathrm{Mg}^{2+}$ Ir ns"; J.S. Feeley, W. M. H. Sachtler; Catal. Lett. 9 1991 377-386

8. "Redispersion of Pd in Y-Zeolites by Chlorine"; Owen C. Feeley, Wolfgang M. H. Sachtler, Applied Catal.드 1991 93-103 
Papers by W. M. H. SACHTLER, acknowledging DOE Support, in press or submitted

1. "Comparison of $\mathrm{Pt} / \mathrm{KL}$ Catalysts Prepared by Ion Exchange or Incipient Wetness Methods"; D.J. Ostgard, L. Kustov, K.R. Poeppelmeier, and W.M.H. Sachtler J. Catal. (accepted 08/28/91)

2. "Detection by CO-FTIR of Incipient Chemical Metal/Support Interaction in $\mathrm{Rh} / \mathrm{SiO}_{2}$ and $\mathrm{Pd} / \mathrm{TiO}_{2}$ "; L.-L. Sheu, W.M.H. Sachtler; J. Molec. Catal. (acc. July 19, 1991

3. "Determination by X-Ray Photoelectron Spectroscopy of the Electronic State of Pd Clusters in Zeolite Y"; A. Yu. Stakheev and W.M.H.Sachtler; Roy. Soc. Chem. Faraday Trans. (accepted 08/15/91)

4. "CO Hydrogenation over PdNi $\quad$ Alloys Encaged in NaY Zeolites" Jennifer $\mathrm{S}$. Feeley, A. Yu Stakheev, Fernando A.P. Cavalcanti, Wolfgang M.H. Sachtler; J. Catal. mailed June 18, 1991, J. Catal. (submitted)

5. Probing of Palladium-Cobalt/ NaY Catalysts by Neopentane Conversion Z Karpinski, Z. Zhang and W.M.H. Sachtler; Catal. Lett. (submitted)

6. "Zeolite Supported Transition Metal Catalysts by Design"; W.M.H.Sachtler, Catalysis Today (submitted) 

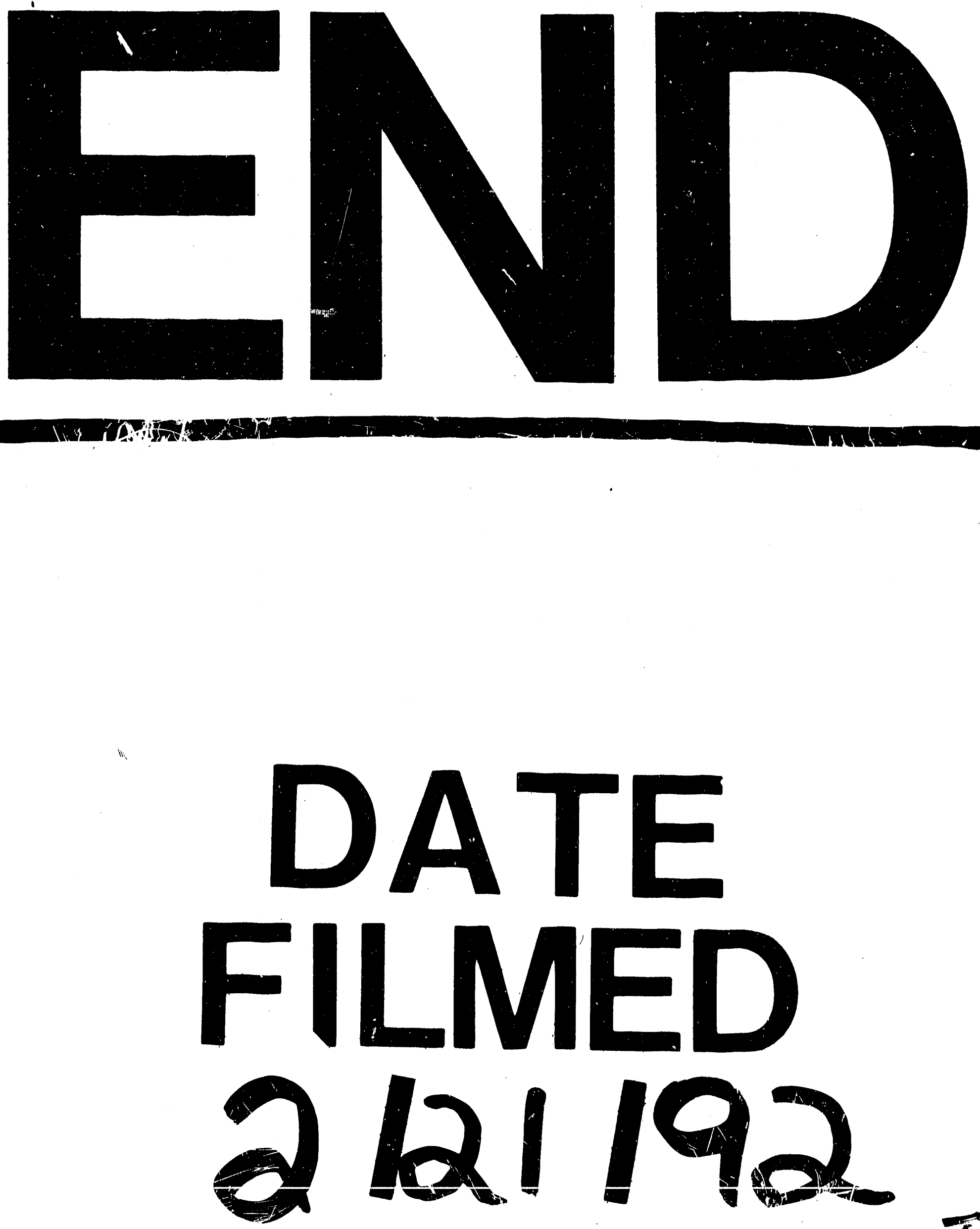

$I$ 
